\title{
El cautivo y su instrumentalización en las relaciones fronterizas tras el Tratado de Guadalupe-Hidalgo/
}

\author{
The cautive and his use as an instrument in the border \\ relationships after de Treaty of Guadalupe-Hidalgo
}

\author{
Francisco Javier Sánchez Moreno \\ Escuela de Estudios Hispano-Americanos, \\ CSIC, Sevilla
}

En este artículo se estudia la función que la búsqueda, rescate y redención de los cautivos de los indios nómadas desempeñó dentro de las relaciones entre México y los Estados Unidos. En líneas generales, proponemos que los cautivos se erigieron en un instrumento para trasmitir un mensaje de contenido político por parte de ambos países, una vez que el Río Bravo se consolidó como frontera internacional. Asimismo, sirvió para incrementar el contacto entre autoridades y personas de ambos países, manifestando una confluencia de los intereses públicos y privados en el fenómeno.

Palabras clave: Cautivos; Redención; Indios nómadas; México; Estados Unidos; Tratado de Guadalupe-Hidalgo; Relaciones fronterizas.

This article studies the role that the search, rescue and redemption of the nomadic Indian captives play inside the relationships between Mexico and United States of America. In general terms, we suggest that the captives were an instrument used by both sides to communicate a political message when the Rio Bravo consolidated as an international border. Moreover it was useful to increase contacts among authorities' and people of both countries. It expresses a public and private convergence of interests in this matter.

KeYwords: Captives; Redemption; Nomadic Indians; Mexico, United States of America, Treaty of Guadalupe-Hidalgo; Border relationships. 


\section{La amenaza de los indios nómadas en los años inmediatos a la guerra}

La firma del Tratado de Guadalupe en febrero de 1848 implicó un profundo cambio en la geopolítica de los países contendientes. No sólo se cederían unos territorios que anteriormente habían pertenecido a la República mexicana, sino que, además, amplias capas de la población se verían afectadas. Al igual que había ocurrido después de la independencia de Texas, unos individuos que habían sido mexicanos pasaban a depender de otro país, con las consecuencias comprensibles que originaron en cuanto a su identidad nacional y personal. Pero, junto a estos problemas, el que más afectó a los habitantes de las villas, ranchos y haciendas en torno al Río Bravo fue la inseguridad que durante los primeros años de la nueva frontera caracterizó su existencia diaria.

La principal explicación de esta situación se hallaba en la permeabilidad de la región fronteriza. Los ataques de abigeos, aventureros y «filibusteros» desde Texas habían sido una realidad desde antes de la guerra entre Estados Unidos y México, y lo continuarían siendo durante las décadas posteriores. Lo mismo cabe decir de las incursiones efectuadas por los comanches, lipanes y otras bandas de indios nómadas relacionadas con ellos.

En este punto conviene señalar que estas agrupaciones tribales habían sido utilizadas por los norteamericanos para hostilizar la frontera mexicana o, al menos, así lo entendieron las autoridades de México a lo largo de la frontera. En efecto, en el noreste, a partir de la intensificación y crecimiento cuantitativo de las incursiones indias, que abarcaban las regiones comprendidas entre San Francisco de Cañas y Cerralvo, en el Estado de Nuevo León, comenzó a difundirse la especie de que eran los mismos militares estadounidenses quienes alentaban a los indios a emprender tales acciones, una vez que se tomó conciencia del deterioro progresivo de las relaciones entre los dos países tras la incorporación de Texas a la Unión. ${ }^{1}$ En el número 88 del Semanario Político del Gobierno de Nuevo León se indicaba, por ejemplo, que:

1 La sospecha de que las autoridades texanas y norteamericanas incitaban a los nómadas a cometer acciones predatorias en territorio mexicano venía de años atrás. Así se interpretó, por ejemplo, por las autoridades mexicanas cuando, de octubre a noviembre de 1844, se comprobó que entre los objetos que llevaban en sus campañas los indios se encontraban medallas con la efigie de George Washington y armas de manufactura estadounidense, como se ve en Semanario Político del gobierno de Nuevo León, tomo IV, jueves 7 de noviembre de 1844, número 45, p. 183. 
Por partes oficiales recibidos en el Gobierno se sabe que la frontera del Departamento, desde San Francisco de Cañas hasta Cerralvo, está plagada de partidas numerosas de indios que en varias direcciones devastan los campos y hostilizan las rancherías. Parece que el gefe de las fuerzas de los Estados Unidos, que cubre actualmente el Departamento de Tejas, ha mandado estas incursiones como principio de una guerra que se pretende hacer a México para arrebatarle lo que es suyo [...].2

Asimismo, Carlos María Bustamante indicaba que los Estados Unidos habían comenzado sus preparativos para la guerra, que se iniciaría como consecuencia de la anexión de Texas, enviando a los indios bárbaros. Estos constituían la vanguardia del ataque, para lo que se habían introducido por Coahuila y Nuevo León, alcanzando Durango. ${ }^{3}$

\section{Las nuevas responsabilidades a partir del Artículo XI del Tratado}

Esta actividad de los guerreros nómadas también se documenta a principios, durante y a finales de la guerra de 1846-1848. Así, por ejemplo, en la primera fecha y desde Chihuahua, las autoridades estatales lamentaban que la seguridad en las vías de comunicación y en los cultivos estaba siempre pendiente de las correrías de los comanches. ${ }^{4}$ Lo mismo ocurría en Durango, donde desde junio de 1846 los ataques a pueblos y haciendas se multiplicaron. De hecho, las caravanas que viajaban por el camino real hasta Santa Fe y los arrieros que atravesaban de Mapimí a Chihuahua se erigieron en blanco de los asaltos de los comanches. Asimismo, en septiembre del mismo año se reportaban ataques dentro del Departamento duranguense, como el acaecido entre la hacienda de La Zarca y el valle de Allende, donde se tomaron cinco cautivos, aparte de ocasionar varias muertes y daños. ${ }^{5}$ Por su parte, en el noreste estas acciones coincidieron con etapas de baja intensidad en el conflicto entre los estadounidenses y México, en momentos prebélicos y durante el final de la guerra. En Sabinas Hidalgo, Nuevo León, su alcalde informaba el 29 de abril del mismo año que el pueblo había sido atacado por una partida de cuarenta indios, sin especificar su adscripción étnica. Por su parte, a finales del conflicto armado, cuando aún no se había sellado la firma del tratado de paz, también la

\footnotetext{
2 Ibidem, jueves 11 de septiembre de 1845 , número 88, p. 367.

3 Pacheco Rojas, 1997, p. 198.

4 Weber, 1988, p. 134.

5 Pacheco Rojas, 1997, pp. 200-201.
} 
actividad india aparece documentada. En efecto, en diciembre de 1847 llegaban al hospital de pobres de San Juan de Dios, en San Luis Potosí, varios indios «bárbaros» de ambos sexos, así como dos cautivos.

Pero, ¿qué ocurriría una vez firmado el Tratado de 1848? Puede sostenerse que los actores implicados implementaron nuevos métodos de actuación, es decir, se adaptaron a una nueva realidad. En este sentido, a partir de febrero, con la cesión de territorios antes mexicanos a los Estados Unidos, la República mexicana traspasó parte del problema al país vecino. Ello era una consecuencia lógica. La persecución de las actividades predatorias, y en consecuencia delictivas, provocadas por los guerreros nómadas que tenían su origen en los Estados Unidos se veía frustrada, puesto que el Río Bravo constituía para los Estados del norte de México una frontera que no podían infringir sin graves consecuencias diplomáticas. ${ }^{6}$

Precisamente ésta sería la clave de la estrategia empleada por apaches, comanches y demás agrupaciones indias nómadas en la frontera. De hecho, era algo que venían practicando desde 1836, pero que ahora consolidarían como principal modo de aprovechamiento de su actividad predatoria a raíz del fortalecimiento de la «línea» fronteriza. En efecto, estas bandas elaboraron una estrategia que podríamos denominar «ambigua», consistente en golpear en ambas orillas del río según lo dictase la conveniencia o la mayor seguridad de éxito. Como consecuencia, los daños en los habitantes de las poblaciones de estas regiones adquirieron dimensiones considerables.

No obstante, la mayor debilidad económica, política y militar mexicana provocaba que fuesen los Estados del norte los más afectados por las correrías. Los datos recopilados por la Comisión Pesquisidora de 1873 que se remontan a los años centrales del siglo XIX manifestarían con el tiempo la magnitud del fenómeno en ese momento, durante la guerra y en los años inmediatamente anteriores. ${ }^{7}$ Ya las Instrucciones que el presidente interino de México, Pedro María Anaya, remitió a sus comisionados en

6 La determinación de las agrupaciones indias agresoras no siempre es posible debido a los datos poco concretos de las fuentes de la época al respecto. Suele ser común la utilización de las palabras bárbaros o salvajes en la documentación de archivo o hemerográfica. Aunque en ese tiempo los ataques solían ser responsabilidad de bandas apaches o comanches, la propia heterogeneidad de las mismas exige ir con cuidado.

7 «Apéndice al informe de la Comisión Pesquisidora del Norte que contiene Estados de las incursiones de los indios, varios documentos sobre sus depredaciones, y muchas otras constancias del mal estado de las relaciones entre las fronteras de México y los Estados-Unidos», en Informe de la Comisión Pesquisidora de la frontera norte..., 1874, I-XLII, donde se contienen las tablas estadísticas de los robos de caballadas, asesinatos y cautivos tomados en los diferentes estados del norte de México desde 1848. 
Ciudad de México, encargados de llevar las negociaciones con los representantes de los Estados Unidos conducentes al tratado de paz, contenían las indicaciones debidas con la finalidad de evitar la impunidad de comanches y apaches. Una de ellas, la número diecisiete, indicaba que se procurase que aquellas tribus que habitaban en alguna parte del territorio norteamericano, en caso de que fuesen expulsadas de esas tierras, no pasaran a los Estados fronterizos mexicanos. Además, se les pedía que obtuviesen de los representantes estadounidenses una cláusula en la que se expresase claramente que éstos se comprometían a no proteger las incursiones de esas tribus indias sobre la frontera, y a no comprarles el producto de sus entradas en suelo mexicano. ${ }^{8}$ Teniendo lo anterior como premisa en las negociaciones, los comisionados mexicanos lograron incluir el artículo XI dentro del contenido del Tratado. En él se dice expresamente:

En atención de que en una gran parte de los territorios que por el presente Tratado van a quedar para lo futuro dentro de los límites de los Estados Unidos, se haya (sic) actualmente ocupada por tribus salvajes que han de estar en adelante bajo la exclusiva autoridad de los Estados Unidos, y cuyas incursiones sobre los distritos mexicanos serían en extremo -/f. 15/- perjudiciales; está solemnemente convenido que el mismo Gobierno contendrá las indicadas incursiones por medio de la fuerza, siempre que así sea necesario; y cuando no pudiere prevenirlas castigará y escarmentará a los invasores, exigiéndoles además la debida reparación: todo del mismo modo y con la misma diligencia y energía con que obraría, si las incursiones se hubiesen meditado o ejecutado sobre territorios suyos o contra sus propios ciudadanos $[\ldots] .{ }^{9}$

Por lo tanto, a partir de entonces el problema indio pasaría a ser una cuestión común entre Estados Unidos y México. Y dentro de la misma se hallaba todo lo relativo a los cautivos:

[...] A ningún habitante de los Estados Unidos será lícito, bajo ningún pretexto, comprar o adquirir cautivo alguno, mexicano o -/f. 15v/- extranjero, residente en México,

8 «Instrucciones que por acuerdo y orden del Excelentísimo señor Presidente Interino de la República Mexicana don Pedro María Anaya, y de conformidad con el voto de sus Ministros, se remiten a sus comisionados en México, General de División don Manuel Rincón y Senadores don Bernardo Couto, don Miguel Aristitáin y don Luis Gonzaga Cuevas, a fin de terminar la guerra que actualmente existe entre nuestra República y la de los Estados Unidos, por medio de un Tratado de Paz a que la primera ha sido invitada de nuevo por Mr. Trist, comisionado al propio objeto por le Gobierno de la segunda», en Algunos documentos sobre el Tratado de Guadalupe..., 1930, p. 111.

9 «Tratado de Paz, Amistad y Límites de 2 de febrero de 1848, entre los Estados Unidos Mexicanos y los Estados Unidos de América» Ibidem, pp. 123-125. Véase también Tratado de Guadalupe Hidalgo, trascripción de Justo S. Alarcón y Manuel de J. Hernández, http://www.cervantes virtual.com/servlet/SirveObras/46826397115794495222202/p0000001.htm, (2 de julio de 2010). 
apresado por los indios habitantes en territorios de cualquiera de las dos Repúblicas, ni los caballos, mulas, ganados, o cualquier otro género de cosas que hayan robado dentro del territorio mexicano (ni en fin venderles o ministrarles bajo cualquier título armas de fuego o municiones) $[\ldots] .{ }^{10}$

El anterior fragmento del Tratado recoge lo que había sido una realidad hasta 1848, puesto que los norteamericanos, a través de su comercio con las agrupaciones indígenas nómadas, propiciaron el aprovechamiento de una práctica que esos grupos venían realizando desde hacía siglos en las Grandes Llanuras. Este comercio con los tratantes procedentes de los Estados Unidos se practicaba en las «casas de trato», en las que era frecuente ver a mexicanos, extranjeros y norteamericanos sufriendo el cautiverio, aunque en el texto no se mencione expresamente a estos últimos. No obstante, a la luz del artículo, no se desechaba la utilización de estas casas, puesto que eran útiles, desde la óptica estadounidense, para agilizar las relaciones con los «bárbaros». Los tratos con los indios se mantenían en estos puntos; lo único que quería desterrarse era la compraventa de los productos obtenidos de las correrías en México, prohibiendo el comercio de caballos, mulas o cautivos por armas y municiones, sin indicarse nada sobre el comercio de otros productos como el alcohol.

Sin embargo, el tráfico, ahora ya ilícito, siguió produciéndose. Cuando menos las reclamaciones de los afectados en territorio mexicano se harían sentir ante el mismo gobierno de la Unión, como atestiguan algunos expedientes conservados en el Archivo Histórico Genaro Estrada de la Secretaría de Relaciones Exteriores de México, correspondientes a los años comprendidos entre 1851 y $1858 .{ }^{11}$ Asimismo, los cautivos no disminuyeron. A modo de ejemplo, podemos señalar que en el Estado de Nuevo León, entre 1848 y 1870, los «bárbaros» tomaron 161 cautivos, correspondiendo la mayor parte a los años comprendidos entre 1850 y $1857 .{ }^{12}$

El problema no se encontraba solamente en que las depredaciones siguieran produciéndose en México, sino que la venta de los productos se

10 Ibidem.

11 Archivo de la Embajada Mexicana en los Estados Unidos de América (AEMEUA), leg. 48, exp. 4, 4f, «Reclamaciones de mexicanos contra el gobierno de Estados Unidos, originadas por las depredaciones de indios bárbaros en la frontera y por la falta de cumplimiento del artículo 11 del Tratado de Guadalupe», 1856. Véase también Ibidem, leg. 50, exp. 1, $171 \mathrm{f}$.

12 «Apéndice al informe de la Comisión Pesquisidora del Norte que contiene Estados de las incursiones de los indios, varios documentos sobre sus depredaciones, y muchas otras constancias del mal estado de las relaciones entre las fronteras de México y los Estados-Unidos»..., I-XXVI. 
continuaba efectuando dentro del territorio estadounidense en estas casas. El testimonio más directo lo proporciona Nicanor Valdés, criador y comerciante de San Juan de Sabinas, Coahuila, quien describe una «casa» situada cerca de Fort Balknap, Texas, en los siguientes términos:

[...] es un grande establecimiento de comercio destinado a mantener el trato con los indios de todas naciones que allí concurren, comprándoles caballada, mulada y cautivos $[\ldots] \cdot{ }^{13}$

Allí vio comanches, kiowas, tancahuas, mezcaleros y otros indios. A continuación señala:

Vio el gran número de cautivos mexicanos que tenían de todas partes, que vendían, así como caballada de fierros mexicanos que diariamente cambiaban por efectos. $\mathrm{La}$ casa dicha, según supo allí mismo, estaba establecida por cuenta del gobierno y no sabe lo que harían con la caballada y mulada que compraban a los indios de la que se robaban de estos puntos, ni cree fueran rescatados todos los cautivos que tenían los indios que hacían la guerra a México, pues repite que eran muchos. El declarante tuvo ocasión de saberlo, porque desde San Antonio, sabiendo que existía esa casa fue preparado con piloncillo, artículo de que son muy amantes los indios, para comprarles cíbolas, como en efecto les compró muchas, estando en los campamentos que tenían éstos en Wichita y también, conforme antes lo ha dicho, en la casa de trato donde permaneció tres meses yendo y viniendo de allí a Nacogdoches con carga a flete. ${ }^{14}$

Aunque este comercio se mantuvo por parte de algunos particulares residentes en los Estados Unidos, también es cierto que, por lo general, ese gobierno procuró los medios para la liberación de los cautivos. Evidentemente el control del tránsito fronterizo de personas y bienes era un asunto en el que ambos países tenían obligaciones, pero la responsabilidad estadounidense en el asunto adquiría una dimensión peculiar ante el hecho de que el beneficio de las correrías lo obtenían los indios en territorio norteamericano, ya fuese en las casas de trato o en las mismas rancherías. ${ }^{15}$

13 Velasco, 1996, p. 130.

14 Ibidem.

15 Hay que tener en cuenta que cuando utilizamos la expresión «beneficio» en el contexto de las incursiones que efectuaban los nómadas, no aludimos solamente a su sentido económico, sino también al prestigio social que obtenían los guerreros cuando aportaban caballos o cautivos a su banda o agrupación tribal. 


\section{La instrumentalización política de los cautivos en las relaciones fronterizas}

Esto se manifestó desde un principio en el caso de la redención de cautivos, puesto que es aquí donde la «instrumentalización» política de éstos se hace más evidente. Pero, ¿qué queremos decir con «instrumentalización» del cautivo? Con esta expresión aludimos al hecho de que, dentro de las nuevas relaciones que se establecieron entre las autoridades de uno y otro lado del Río Bravo, la búsqueda, liberación y entrega de los mexicanos que se hallaban prisioneros de los «bárbaros» se erigían en unos medios de expresión de la soberanía y control efectivo de los territorios recientemente adquiridos, desde el punto de vista estadounidense. Pero también podían convertirse en un medio para reclamar el cumplimiento de lo estipulado en el Tratado por parte de las autoridades mexicanas. Ya comentamos que el Artículo XI permitía que la responsabilidad de los ataques de los indios que partían del lado norteamericano de la frontera recayese en ese gobierno, $y$, puesto que los cautivos eran parte de los ataques, el artículo mencionado responsabilizó al gobierno de la Unión de los que se hallasen en su territorio en poder de los indios. Según el Tratado:

$\mathrm{Y}$ en caso de cualquier persona o personas cautivadas por los Indios dentro del territorio mexicano sean llevadas al territorio de los Estados Unidos, el Gobierno de dichos Estados Unidos se compromete y liga de la manera más solemne, en cuanto le sea posible, a rescatarlas, y a restituirlas -/f. 16r/- a su país, o entregarlas al agente o representantes del Gobierno mexicano, haciendo todo esto tan luego como sepa que los dichos cautivos se hallan dentro de su territorio, y empleando al efecto el leal ejercicio de su influencia y poder. Las autoridades mexicanas darán a las de los Estados Unidos, según sea practicable, una noticia de tales cautivos; y el agente mexicano pagará los gastos erogados en el mantenimiento y remisión de los que se rescaten, los cuales entretanto serán tratados con la mayor hospitalidad por las autoridades Americanas del lugar en que se encuentren. Mas si el Gobierno de los Estados Unidos antes de recibir -/f. 16v/- aviso de México, tuviere noticia por cualquier otro conducto de existir en su territorio cautivos mexicanos, procederá desde luego a verificar su rescate y entrega al agente mexicano, según queda convenido. ${ }^{16}$

Por consiguiente, desde 1848 encontramos referencias a autoridades del Gobierno de la Unión implicadas en el proceso de liberación. En una

16 «Tratado de Paz, Amistad y Límites de 2 de febrero de 1848, entre los Estados Unidos Mexicanos y los Estados Unidos de América», pp. 123-125. 
notificación de Juan Manuel Maldonado a Antonio María Jáuregui, fechada en junio de 1851 en la villa de Rosas, se remitía una copia del expediente relativo a la entrega de cincuenta cautivos mexicanos rescatados en Texas, y recibidos en Fort Duncan. ${ }^{17}$ Lo mismo ocurriría el 22 de junio de 1851 cuando el comandante militar de Fort Duncan entregó a las autoridades mexicanas diecisiete jóvenes que habían sido capturados entre 1843 y 1850. ${ }^{18}$ En otra comunicación entre esas mismas autoridades, datada en la colonia de Monclova Viejo en julio de 1851, se indica que habían sido entregados nuevamente por el comandante de Fort Duncan los mexicanos José María Gallardo, natural de Monclova, e Ignacio García, natural de Durango, quienes habían sido raptados en la hacienda de Adjunta. ${ }^{19}$ En casos como los citados la entrega se hacía dentro de un establecimiento militar estadounidense, lo cual, fuese de manera consciente o no, comunicaba un mensaje de contenido político, que no podía ocultar la imagen de gesto aparente de buena voluntad. ${ }^{20}$ Pretendía manifestar que la Unión sí ejercía un control real sobre el territorio, capaz de ofrecer seguridad física y jurídica a los habitantes de la frontera, a diferencia de las autoridades mexicanas, incapaces de proporcionar protección y ejercer la soberanía en su propio espacio nacional. No debe olvidarse que la futura Comisión Pesquisidora se crearía para elaborar un informe que rebatiese la opinión generalizada en los Estados Unidos acerca de la incapacidad mexicana sobre la garantía de la seguridad fronteriza. Todo lo cual no deja de indicar que la sombra del expansionismo estadounidense siempre estaría presente sobre la frontera desde el final de la guerra. ${ }^{21}$

17 Archivo General del Estado de Coahuila (AGEC), Fondo de Colonias Militares de Oriente (FCMO), C14, F2, E22, 8F, «Juan Manuel Maldonado, subinspector de las Colonias Militares de Oriente, remite a Antonio María de Jáuregui, inspector general de las mismas, copia del expediente relativo a la entrega de 50 cautivos mexicanos rescatados en Texas a comanches y lipanes, y recibidos por aquellas autoridades en el Fuerte Duncan», villa de Rosas, junio de 1851.

18 Rodríguez, 1998, p. 187.

19 AGEC, FCMO, C14, F3, E45, 2F, «Juan Manuel Maldonado, subinspector de las Colonias Militares de Oriente, informa a Antonio María Jáuregui, inspector general de las mismas, que fueron entregados por el comandante del Fuerte Duncan los cautivos José María Gallardo, natural de Monclova e Ignacio García, natural de Durango quienes fueron robados por los indios en la hacienda de Adjunta», colonia de Monclova Viejo, julio de 1851.

20 Ibidem.

21 Así lo manifestarían las expediciones posteriores sobre territorio mexicano por parte del ejército de los Estados Unidos, como la efectuada por el coronel Ranald Mackenzie en 1873. Véase Rodríguez, 1998, pp. 251-259 para conocer el contexto en el que se llevó a cabo esta expedición contra los kikapú. 
Hay que tener en cuenta que, aunque entre 1848 y 1853 México vivía una relativa calma en lo que se refiere a la estabilidad en el cargo de su presidente, ${ }^{22}$ atravesaba una difícil situación económica, que la indemnización de guerra sólo alivió momentáneamente. Esta debilidad económica se trasladó al norte de diversas maneras, pero en el plano político y militar se tradujo en un ineficiente establecimiento de las colonias militares. No es este el lugar para detallar las características del sistema defensivo de estas colonias; lo que nos interesa resaltar es que se idearon, junto a los Planes de Defensa aprobados en los Estados y localidades del norte a partir de 1849, para organizar la defensa de un territorio que en esas fechas se hallaba despoblado y que podía ser objeto de los asaltos de apaches y comanches, con el menoscabo subsiguiente para la soberanía nacional. ${ }^{23}$ Sin embargo, como indica Martha Rodríguez:

[...] Las colonias militares enfrentaron un sinnúmero de problemas que fueron desde el reclutamiento de soldados, la paga, manutención y equipamiento, hasta serias dificultades entre ellas y las autoridades civiles, debido a la puesta en marcha de distintas estrategias en la guerra contra el «bárbaro». A consecuencia de ello, y a escasos cinco años de su creación, las colonias militares fueron suprimidas el 25 de abril de $1853[\ldots] . .^{24}$

Ante el fracaso de estas medidas, se arbitraron otras más inmediatas como la promoción de la inmigración de los kikapú y los seminoles, la organización de expediciones punitivas contra las rancherías de indios que habían atacado, robado y cautivado las regiones fronterizas, así como la elaboración de un discurso cifrado en el exterminio de estos indios «bárbaros». Así, como consecuencia de una incursión que los «bárbaros» efectuaron en junio de 1851, se aprestó una expedición que actuó durante la primera mitad de julio, tal como recogen los números 31 y 32 del Órgano oficial del Supremo Gobierno del Estado Libre de Nuevo León, al mismo tiempo que desde las diferentes localidades se reportaban ataques indios y contraataques por parte de las poblaciones y puestos militares. No sería exacto pensar en la ineficiencia absoluta de estas expediciones. Casos como los recogidos en el número 31 del citado periódico oficial indican

22 Puesto que, a diferencia de lo sucedido en los años anteriores, José Joaquín Herrera y Mariano Arista duraron más de un año en sus cargos.

23 Por ejemplo, hacia 1848 el Estado de Coahuila contaba solamente con unos 75.340 habitantes, tal como señala Rodríguez, 1998, p. 70.

24 Ibidem. 
que las autoridades civiles y militares mexicanas eran las mejor situadas para liberar a los cautivos. ${ }^{25}$ La imposibilidad para impedir las depredaciones de lipanes y comanches se debía más bien a una falta de recursos materiales y humanos, lo que explica que la autodefensa vecinal constituyese la base del sistema. Este apoyo comunitario era necesario, pero también preferido por los habitantes de la frontera. En efecto, los propios vecinos organizaban expediciones punitivas ante la sensación de ineficacia del ejército en la persecución de los «bárbaros»; en otras ocasiones su aportación a las expediciones militares era fundamental. Algo que también incluirían los Planes de Defensa elaborados en aquellos años siguiendo la práctica establecida en toda la frontera desde hacía décadas.

Por ejemplo, el Plan de Defensa de los Estados invadidos por los bárbaros, de 1849, buscaba una conjunción de fuerzas entre la guardia nacional móvil, el resto del ejército y la población que se estableciese en las colonias militares. Aunque estas últimas no se desarrollasen plenamente debido a los problemas presupuestarios y de competencias señalados, es evidente que el espíritu que las animaba descansaba en la idea de la solidaridad vecinal, como el Artículo 21, III señala:

III. Es obligación de las municipalidades perseguir dentro de sus límites y en combinación con los pueblos inmediatos, á los bárbaros, con la Guardia Nacional móvil o sedentaria. ${ }^{26}$

$\mathrm{Y}$ en el punto siguiente se señala que desde las haciendas y ranchos también se debía perseguir a los agresores dentro de sus límites, en combinación con los habitantes de las propiedades vecinas. ${ }^{27}$ Hay que tener presente que esta inevitable colaboración entre los vecinos en las comunidades del norte apoyaba el sostenimiento de la identidad nacional en unas tierras frecuentemente mal defendidas por el gobierno central. ${ }^{28} \mathrm{Y}$ al mismo tiempo ahorraba costos defensivos al mismo.

Sea como fuere, dentro de los respectivos Estados era inevitable mantener esta tradición de solidaridad defensiva. De hecho, observamos que en

25 «Gobierno del Estado», Órgano oficial del Supremo Gobierno del Estado Libre de Nuevo León, tomo II, Monterrey, jueves 24 de julio de 1851, número 31. En este número se menciona a tres arrieros y un muchacho que fueron liberados de los indios el 11 de julio a resultas de una expedición organizada contra los indios por el primer batallón de la guardia móvil del Estado de Nuevo León.

26 Plan de Defensa de los Estados invadidos por los bárbaros, propuesto por la Junta de Representantes, creada por la Ley de 24 de abril del presente año, 1849, p. 22.

27 Idem.

28 Ibidem, p. 5. 
los planes de defensa estatales se mantuvo el mismo tenor que la normativa aprobada desde México. Así, en el Artículo 9 del Plan para la defensa del Estado de Coahuila invadido por los bárbaros se recoge lo que sigue:

Art. 9. ${ }^{\circ}$ Es obligación natural de todos los habitantes de Coahuila contribuir simultáneamente con sus personas é intereses á la defensa común de las localidades en donde residen, para resistir la invasión de los salvages, repeliendo la fuerza con la fuerza; y obedeciendo las órdenes y disposiciones emanadas de la autoridad civil de quien dependen. ${ }^{29}$

Idea que vuelve a encontrarse en los siguientes Artículos 10, 11 y 12 , donde se especifica la manera de proceder de los vecinos, que estaban obligados a reunirse al toque de alarma sin posibilidad de eludir la obligación de cooperación, especialmente en poblaciones poco numerosas. Asimismo, si el peligro era inminente, podían expropiarse propiedades muebles e inmuebles de los habitantes de la localidad amenazada. Junto a estas obligaciones militares existían otras obligaciones informativas, puesto que debían dar noticia puntual de la presencia de indios en las inmediaciones de su localidad.

De cualquier forma, hay que tener en consideración que, puesto que podían transcurrir varias horas desde el momento del ataque y la toma de los cautivos hasta que pudiera organizarse la expedición de rescate, los asaltantes tenían un margen más que suficiente para escapar en movimientos rápidos hacia el otro lado del Río Bravo, donde los mexicanos ya no tenían capacidad de actuación. En consecuencia, la colaboración con las autoridades militares fronterizas de la Unión era inevitable. Por lo tanto, volvemos a apreciar que la cuestión de los cautivos y de los robos de caballada y mulada tenía a partir de ese momento un marcado carácter de política internacional.

\section{El reintegro de los gastos de la redención de los cautivos}

Para los mandos norteamericanos la existencia de las casas de trato agilizó la búsqueda y liberación de los cautivos. No obstante, no era algo que hiciesen de una manera gratuita. Como se indica en el ya citado artículo del Tratado de Guadalupe, ya fuesen liberados por particulares o por funcio-

29 Plan para la defensa del Estado de Coahuila invadido por los bárbaros...., 1849, pp. 19-20. 
narios norteamericanos, se esperaba que, tras la obtención de los cautivos y su entrega a las autoridades mexicanas, éstas reintegrarían lo desembolsado a los primeros. ${ }^{30}$ Aunque del texto del Tratado no parece desprenderse que los estadounidenses cobraran ningún tipo de comisión por ejercer esta labor, sino que únicamente exigían el reintegro de lo gastado, ${ }^{31}$ no sólo en la compra a los indios, sino también en la manutención de los cautivos hasta la entrega a la parte mexicana, podían igualmente cometerse abusos. El 10 de mayo de 1852 un comunicado del ministro de Guerra y Marina al inspector general de las Colonias Militares de Oriente señalaba lo siguiente:

[...] porque ha llegado el caso de que debe llamarse la atención del Gobierno de los Estados Unidos, respecto de los abusos que se cometen y pueden cometerse en lo sucesibo (sic) tanto en la exajeración (sic) de los gastos que causen los cautivos que se rescaten de las tribus de los indios residentes en aquel territorio por los agentes de aquella nación, como por la mala calificación que se haga de los verdaderos cautivos que desean volver a su Patria y de los que voluntariamente prescindan de ella. Debo advertir a Vuestra Excelencia que por parte de este Ministerio se mandan pagar todos los gastos que causaron tanto los once cautivos presentados, como los que se dice hicieron los diez y seis que se le jugaron a los agentes de los Estados Unidos; con el objeto de que se vea que el Gobierno Mexicano cumple explícitamente con los convenios del tratado de Guadalupe $[\ldots]^{32}$

Este testimonio muestra lo que venimos tratando; es decir, revela que los cautivos y el contexto de su liberación se constituían en instrumentos de las relaciones entre ambos países. Pero también que las actitudes por todas las partes implicadas en el proceso no siempre eran limpias. El hecho de que el ministro de Guerra y Marina recalcase que el Gobierno mexicano cumplía con sus obligaciones derivadas del Tratado de Guadalupe buscaba en último término despejar las dudas que, como indicamos, existían dentro

30 Como ejemplo podemos citar AGEC, FCMO, C18, F5, E51, 1F, en el que Manuel María Sandoval, ministro de Guerra y Marina, comunica al inspector general de las Colonias Militares de Oriente, que el presidente de la República ordena que se paguen los rescates de los cautivos a los comisionados del Gobierno americano, de acuerdo a lo que quedó establecido

31 Ibidem, C14, F4, E64, 2F, «Robles, ministro de Guerra y Marina, comunica al inspector general de las Colonias Militares de Oriente, haber puesto en conocimiento al Presidente de la República acerca de su nota, donde adjunta la cuenta de 338 pesos que se erogaron en el rescate de 17 cautivos que tenían los indios comanches y lipanes, así como de las medidas que se proponen para que en lo sucesivo, no se erogue por la Hacienda Pública el desembolso para el rescate de cautivos», México, julio de 1851 .

32 Ibidem, C17, F2, E14, 1F, «Robles, ministro de Guerra y Marina, transcribe al inspector general de las Colonias Militares de Oriente, una comunicación del ministro de Relaciones, relativa a que debe llamarse la atención al gobierno de los EEUU por los abusos que se cometen en la exageración de los gastos que causan los cautivos mexicanos», México, mayo de 1852. 
de la administración y la sociedad estadounidense acerca de la capacidad y de la buena fe de México en el respeto a lo estipulado. En este caso concreto, en el cumplimiento de los pagos a la administración norteamericana para compensarlos por los gastos verificados en la redención y manutención de los cautivos mexicanos liberados. Y encontramos otros documentos de los mandos fronterizos que insisten en este punto, es decir, quieren dejar claro que se cumplían los compromisos. Así, por ejemplo, en julio de 1852 Manuel María Sandoval, ministro de Guerra y Marina, reiteraba al inspector general de las Colonias Militares de Oriente, que el presidente de la República ordenaba pagar los rescates de los sujetos liberados a los representantes norteamericanos..$^{33}$

Asimismo, el documento trascrito nos da la oportunidad de comprobar que las autoridades estadounidenses encargadas de llevar a efecto el proceso de liberación podían abusar de su posición, tanto exagerando los gastos como incluyendo en el proceso de redención a cautivos que no querían volver a sus familias, o por medio de ambos expedientes al mismo tiempo. Con lo anterior se buscaría obtener un beneficio económico adicional.

Determinadas formas de llevar a cabo la redención ayudarían a que se produjesen este tipo de situaciones. Una de ellas tenía como protagonistas a sujetos expertos en el trato con los indios, en algunos casos militares al servicio del Estado, quienes se hacían cargo de la redención de los cautivos. Estos sujetos presentaban después los liberados o una lista de los mismos ante las autoridades, las cuales adelantaban esta cantidad por cuenta de los familiares del cautivo, siempre y cuando existiese liquidez; éste es el caso de Espiridión Solís, rescatado por Manuel Múzquiz. En efecto, el 17 de mayo de 1850 una notificación de Ángel Frías, del Congreso del Estado de Chihuahua, al gobernador del Estado de Coahuila indicaba lo siguiente:

Entre varios cautivos que ha presentado en este gobierno el ciudadano Manuel Múzquiz, rescatados a los indios bárbaros en la colonia de San Carlos, se encuentra un joven llamado Espiridión Solís, hijo de Ricardo y de M. ${ }^{\mathrm{a}}$ Isabel Solis, vecinos de Monclova, en ese Estado. En tal virtud, tengo el honor de comunicarlo a Vuestra Excelencia para su conocimiento, manifestándole que por no haber en lo absoluto en este fondo de donde satisfacer la cantidad de setenta y cinco pesos que es a lo que

33 Ibidem, C18, F5, E51, 1F, «Manuel María Sandoval, ministro de Guerra y Marina comunica al inspector general de las Colonias Militares de Oriente, que el Presidente de la República ordena que se paguen los rescates de los cautivos a los comisionados del gobierno americano, de acuerdo a lo que quedó establecido», México, julio de 1852. 
importó el rescate de dicho cautivo, según ha acreditado el mencionado Múzquiz, no lo ha verificado este Gobierno a pesar de los deseos que tiene de cooperar al logro de obra tan humana, como lo es la redención de cautivos. ${ }^{34}$

Unos problemas financieros de los que se hace eco el gobierno coahuilense, que también atravesaba apuros de este tipo, como señala la respuesta a la anterior carta cuando indica que la cantidad exigida:

[...] será satisfecha por el gobierno de mi cargo a la persona que se asigne o la remitiré por medio de libranza, luego que sea posible conseguirla suplicando a Vuestra Excelencia que el citado cautivo se sirva remitirlo [...] en la primera oportunidad que se presente. ${ }^{35}$

Aunque en el caso que mencionamos Manuel Múzquiz condonó los gastos originados por el rescate y el traslado de Espiridión Solís y otra cautiva hasta sus familias, ${ }^{36}$ lo habitual fue que se exigiesen las cantidades pagadas. Así le ocurrió a la madre de Ventura Garza, quien en 1865 dio 300 pesos por el valor de los caballos y productos entregados por el vecino del Paso del Norte que había rescatado a su hijo de manos de los indios. ${ }^{37}$ En consecuencia, una vez que se pagaba a estos intermediarios, los sujetos redimidos pasaban a estar bajo custodia de la autoridad fronteriza, permaneciendo así la situación hasta que no se costease el dinero del rescate y la manutención. Este tipo de tratantes mantendrían una actividad que se extendía a ambos lados de la frontera, si bien nosotros hemos aportado documentos relacionados a sujetos que ya se encontraban en territorio mexicano.

34 Archivo General del Estado de Coahuila (AGEC), Fondo Siglo XIX (FSXIX), C3, F6, E3, $3 \mathrm{~F}$ «Ángel Frías, del Congreso del Estado de Chihuahua, notifica al gobernador del Estado de Coahuila que de los cautivos rescatados de los indios bárbaros, uno responde al nombre de Espiridión Solís el cual es originario de Monclova, por lo que se le solicita cubra el importe de lo que se gastó en el mencionado rescate», Chihuahua, 17 de mayo de 1850.

35 Ibidem.

36 AGEC, FSXIX, C4, F4, E6, 3F «[...] Impuesto de las dos notas de usted de 6 del presente, relativas a los cautivos de ese Estado, Espiridión Solis y Margarita Espinosa; paso a manifestarle en debida contestación que el C. Manuel Múzquiz indemnizó en este Estado la cantidad de ciento setenta pesos que importaron los rescates de los citados cautivos, con objeto de trasladarlos al seno de sus familias, como lo verificó llevándolos consigo y a sus expensas; por consecuencia no tiene el gobierno del digno mando de Vuestra Excelencia que reintegrar a este, de la cantidad mencionada que se había satisfecho por los fondos de este Estado [...]», como consta en «Ángel Frías, del Gobierno del Estado de Chihuahua, comunica al Gobernador de Coahuila que el c. Manuel Múzquiz indemnizó la cantidad de \$ 172.00 pesos por los rescates de los cautivos Espridión Solis y Margarita Espinoza», Chihuahua, 28 de junio de 1850 . 


\section{Relaciones entre los ámbitos público y privado dentro del proceso de redención}

También se daba el supuesto de que los propios familiares de los sujetos que habían sido raptados por los indios tomasen la iniciativa de la búsqueda y liberación de aquellos. Éste fue el caso de Alejandro García, que partió él mismo a rescatar a sus dos hijos, Juan y Lucio, pagando dos pesos diarios a cinco hombres durante 22 días para que le acompañaran. Finalmente sólo pudo recuperar a uno de sus hijos que salió de su cautiverio huyendo, mientras que al otro no consiguió liberarlo a pesar de las promesas del indio Costalitos. ${ }^{38}$

Ejemplos como el anterior exigían a los familiares liquidez, no sólo para la manutención durante los desplazamientos, sino también para el pago a autoridades fronterizas, como le ocurrió al mismo Alejandro García en el Águila, con el jefe militar local ${ }^{39}$ Si faltaban estas cantidades, la redención se hacía más difícil. No obstante, podía darse la circunstancia de que se lograse salir de los aduares previo pago por un particular que se hacía cargo de la situación del prisionero. Esta fórmula la encontramos en cautivos que permanecieron en los Estados Unidos tras su liberación trabajando al servicio de aquel que los había redimido. Tal fue el caso de Francisco Treviño, quien después de salir de su cautiverio entre los comanches, pasó a vivir con un tal capitán Johns, y después con un abogado de nombre Williams. Tras pasar dos años, se trasladó con el coronel Cook a San Antonio. Esta etapa de su vida se prolongaría unos tres años, probablemente entre 1837 y 1840, pues él mismo señala que en este año pasó a México. ${ }^{40}$ Aunque este ejemplo es anterior a la firma del Tratado de Guadalupe-Hidalgo, sirve para ilustrar la continuidad de determinadas prácticas relacionadas con los cautivos.

Una vez liberados, y viviendo en los Estados Unidos, podía darse la circunstancia de que solicitasen información acerca del paradero de sus familiares en México. Aunque en estos supuestos no puede hablarse de una instrumentalización, al ser los propios cautivos los que actuaban, es interesante ver cómo era necesario un constante diálogo entre las autoridades mexicanas y estadounidenses. Pese a que cada país tenía sus propios inte-

\footnotetext{
37 Velasco, 1996, p. 99.

38 Ibidem, pp. 112-113.

39 Idem.

40 Ibidem, pp. 44-45.
} 
reses, como hemos visto, eran conscientes de la necesidad de un contacto lo más fluido posible para determinar la situación de unos sujetos que, en último término, se encontraban en una situación anómala dentro del territorio de la Unión.

El caso de Lino Remigio ilustra lo que decimos; aunque es posterior a los años inmediatos a la firma del Tratado, muestra que el problema del cautiverio se mantuvo constante en las relaciones entre los gobiernos mexicano y estadounidense. Su nombre aparece en una noticia del periódico $E l$ Coahuilense, el 4 de octubre de 1866. En ella la delegación mexicana en Washington se dirige a su gobierno con objeto de conocer el paradero de la familia de este muchacho raptado por los «bárbaros» a la edad de 7 años, y llevado a territorio de los Estados Unidos. El joven permaneció entre los indios hasta que logró liberarse en tiempos de la Guerra de Secesión, gracias a la ayuda de H. Carruth, pasando a vivir en Kansas. Afirmaba que su padre se llamaba Luis Remigio y expresaba su deseo de saber de su familia y de reunirse con ella después de tanto tiempo. Por este motivo desde el periódico se hizo un llamamiento a los allegados para saber su situación. En caso de que se reuniesen noticias al respecto, el periódico indicaba que se hiciera saber al Gobierno y éste, por su parte, lo comunicaría a la legación. ${ }^{41}$ La noticia volverá a repetirse el 11 de octubre, con el mismo tenor. ${ }^{42}$ La solicitud de la embajada llegó a los Estados fronterizos de Tamaulipas, Nuevo León, Coahuila y Chihuahua. ${ }^{43}$

El hecho de que algunos pasasen a vivir con aquellos que los habían redimido permite acercarnos a otro fenómeno análogo: el depósito de los sujetos liberados en casas particulares hasta el momento de la entrega a los familiares. Es otra muestra de cómo las esferas de lo público y lo privado interferían entre sí en el tema que estamos tratando tanto en los Estados Unidos, como en México. Asimismo, constituye un ejemplo de instrumen-

41 El Coahuilense. Periódico del Gobierno de Estado Libre de Coahuila de Zaragoza, Tomo II, Saltillo, viernes 4 de octubre de 1867, número 13, p. 4. El nombre del reverendo H Carruth aparece en AEMEUA, Leg. 64, Exp. 9, 10f.

42 El Coahuilense..., Tomo II, Saltillo, viernes 11 de octubre de 1867, número 15, p. 4.

43 Véase AEMEUA, Leg. 64, Exp. 9, 10f. El nombre del reverendo James H. Carruth también aparece en el documento. Además, en «Provisions of the Act of the Legislature of the State of Kansas, on February 15, 1866 stated that marriage between people of color was now legal. Couples who were married by their traditional methods now recorded their marriages at the Court House», KSGenWeb Internet Genealogical Society, http://skyways.lib.ks.us/genweb/archives/douglas/marriage/marr 1867.htm, (2 de julio de 2010), consta que este sacerdote ofició en matrimonios de ciudadanos negros en el Estado de Kansas en 1867 y 1868, precisamente en las fechas en las que Lino Remigio residía en aquel Estado; es probable que Lino Remigio estuviese a su servicio. 
talización, si bien en el interior de los respectivos países. En efecto, una vez que los prisioneros ${ }^{44}$ salían de las rancherías, los mandos fronterizos decidían dónde alojar a los mismos y quien arrostraría los gastos de la manutención ${ }^{45} \mathrm{El}$ hospedaje en una casa particular constituía un medio para abaratar éstos, siendo una práctica realizada a ambos lados del Río Bravo. En julio de 1851 Juan Manuel Maldonado, subinspector de las Colonias Militares de Oriente, informaba al inspector general de las mismas haber entregado a Florencio Herrera, inválido que perteneció a la antigua compañía del presidio de Río Grande, los sujetos Romano Sánchez y Benigno Santillana, que habían estado prisioneros entre los indios, a solicitud del alcalde de Bustamante, Nuevo León. ${ }^{46}$ José Antonio de Arredondo, capitán de la colonia militar de Guerrero, informa en mayo de 1852 al inspector general de las Colonias Militares de Oriente, desde Piedras Negras, del fallecimiento de Valentín Sánchez, a causa de las heridas que recibió en Béjar en la casa donde vivía después de salir de su cautiverio. ${ }^{47}$ En enero de 1854, unos vecinos pusieron bajo la custodia de Jacobo Elizondo a un sujeto que habían recuperado en las cercanías de la hacienda de Patos, después de una expedición punitiva contra los «bárbaros», que habían asaltado dicha hacienda ${ }^{48}$ El 9 de julio de 1858 Antonio Ochoa, del gobierno del Estado de Chihuahua, comunicaba al gobernador de Nuevo León y Coahuila, Santiago Vidaurri, que se recomendaba al señor José Cordero,

44 Debemos tener presente que el término «prisionero» puede resultar forzado cuando escribimos acerca de los capturados por los indios, pues la naturaleza del cautiverio entre los nómadas lo hacía inviable; aparte de la inexistencia de prisiones en el sentido occidental, el proceso de integración o de adaptación a la vida de la banda lo hacía innecesario en muchos casos. Si hacemos uso del mismo es sólo para aligerar la lectura y evitar redundancias terminológicas.

45 Véase el Plan para la defensa del Estado de Coahuila invadido por los bárbaros..., 1849, p. 12.

46 AGEC, FCMO, C14, F4, E66, 2F, «Juan Manuel Maldonado, subinspector de las Colonias Militares de Oriente, informa a Antonio María Jáuregui, inspector general de las mismas, haber entregado a Florencio Herrera, inválido de la antigua compañía presidial de Río Grande, los cautivos Romano Sánchez y Benigno Santillana, a solicitud del alcalde de Bustamante en el estado de Nuevo León», villa de Rosas, julio de 1851. El depósito de los cautivos duraría hasta que estuviesen «[...] en manos de sus padres y deudos». También se encargarían de los cautivos León Cruz y José María Rocha por encargo de sus padres y del alcalde de la villa.

47 Ibidem, C17, F4, E33, 2F, «José Antonio de Arredondo, capitán de la colonia militar de Guerrero, informa al inspector general de las Colonias Militares de Oriente, acerca del fallecimiento del cautivo Valentín Sánchez, a causa de las heridas que recibió en Béjar en la casa donde vivía», Piedras Negras, mayo de 1852.

48 Ibidem, FSXIX, C1, F6, E3, 6F, «Manuel Roble del juzgado de paz de este lugar, comunica a la prefectura del departamento de Saltillo, lo relativo a que ya salió la partida de gentes que perseguiría a los indios y a su regreso han traído un cautivo, 74 bestias y otros objetos de pillaje», Hacienda de Patos, 26 de enero de 1854. 
vecino de Chihuahua, el envío del cautivo Leandro Borrego por orden superior; por consiguiente éste había estado hospedado en la casa de aquel. ${ }^{49}$

El depósito en casa de un vecino de la localidad a la que llegaba el cautivo era algo usual, aun cuando su liberación no fuese resultado de una redención, sino de una fuga. En efecto, hasta ahora hemos tratado de aquellos individuos respecto de los cuales las autoridades o particulares intervinieron para liberarlo, pero igualmente frecuente fue el caso de los que, por iniciativa propia o ayudados por un tercero, lograron salir de los aduares. Hemos indicado que podían recibir ayuda; ello era inevitable puesto que al encontrarse las rancherías en lugares aislados, a los que se llegaba después de varias jornadas de camino a caballo, una travesía en solitario resultaba peligrosa, incluso aunque no lo persiguiesen los captores. Los detalles de su huída ocasionalmente aparecen en el relato o declaración de la víctima del cautiverio; evidentemente se producía en un momento de descuido de los captores, e implicaba el caminar varias jornadas completamente solo por el desierto, como le ocurrió a Juan García al escapar de los comanches. ${ }^{50}$ Macedonio Perales también anduvo durante nueve días hasta llegar a San Antonio de Béjar, donde se unió a unas carretas que se dirigían a México. ${ }^{51}$ En otras ocasiones se recurría al engaño: Juan Vela Benavides, después de ver frustrados sus intentos de que un alemán lo rescatara por las objeciones del comanche que lo había capturado, decidió huir hacia Santa Fe en Nuevo México, aprovechando una caravana que se dirigía a esta ciudad. Para hacerlo posible engañó a los indios haciéndoles creer que iba a recorrer las rancherías cercanas.

El hambre y las privaciones eran habituales en los que lograban fugarse. Por ello mismo los gastos de manutención a los que aludimos no serían tampoco desdeñables para los particulares que tenían que arrostrarlos. Se comprende así el interés de las administraciones estadounidense y mexicana por recuperar lo adelantado, pero también las comunicaciones entre autoridades mexicanas que reiteran la voluntad de su gobierno de cumplir con sus obligaciones pecuniarias, como ya vimos más arriba.

49 Ibidem, C3, F6, E1, 2F, «Antonio Ochoa del gobierno del Estado de Chihuahua, comunica al gobernador del Estado de Nuevo León y Coahuila, Santiago Vidaurri, lo relativo a que se recomienda al señor José Cordero vecino de Chihuahua, el envío del cautivo Leandro Borrego por orden superior», Chihuahua, 9 de julio de 1858.

50 Velasco, 1996, p. 116.

51 Ibidem, p. 71. 
Concluimos por tanto que, a pesar de los desencuentros provocados por la defensa de los intereses respectivos, los cautivos y su proceso de redención sirvieron como instrumentos para canalizar un diálogo trasfronterizo entre las autoridades civiles y mandos militares de ambos lados de la frontera. Un diálogo que exigía gastos y responsabilidades mutuas. La continuidad de las depredaciones nos hace pensar en la dificultad de la persecución de los guerreros nómadas, pero también en problemas de tipo político. Para los norteamericanos, fueron sus colegas del otro lado de la frontera los que no se mostraron capaces de asegurar la soberanía de su propio territorio nacional. Era «legítimo», por lo tanto, mantener un discurso anexionista, puesto que poniendo bajo control estadounidense los extensos Estados del norte de México se podría asegurar la integridad física y económica de los ciudadanos de la Unión que se estaban asentando en el territorio. Aunque tras el Tratado de 1853 los norteamericanos se desentendieron de las cláusulas del Artículo XI, la actitud permaneció hasta el estallido de la Guerra de Secesión. Por el contrario, para los mexicanos encargados de la administración de los territorios del norte era la falta de interés norteamericano la causa principal de que continuara la inseguridad en los mismos, cuando no la connivencia en el tráfico de las mercancías robadas por los indios durante las incursiones.

Pero este diálogo no sólo tenía matices negativos. Lo habitual fue la colaboración de las autoridades para mejorar la situación de los cautivos. En último término, se pretendía normalizar la situación, jurídica pero también social, de unos individuos que estaban en territorio extranjero; unos sujetos que demostraban la permeabilidad de la frontera y el dinamismo de la identidad colectiva y personal en el Río Bravo.

Recibido el 26 de enero de 2010 Aceptado el 08 de julio de 2010

\section{Bibliografía}

Algunos documentos sobre el Tratado de Guadalupe y la situación de México durante la invasión americana, prólogo de Antonio de la Peña y Reyes, México, Secretaría de Relaciones Exteriores, 1930.

Brooks, James: Captives and cousins: Slavery, Kinship, and Community in the Southwest Borderlands, Chapel Hill, University of North Carolina Press, 2002. 
DeLay, Brian: War of a thousand deserts. Indian Raids and the US-Mexican War, Yale, Yale University Press, 2009.

De la Cruz Pacheco Rojas, José: «Durango entre dos guerras», en Vázquez, Josefina Zoraida (coord.), México al tiempo de su guerra con Estados Unidos, México, Secretaría de Relaciones Exteriores, Fondo de Cultura Económica, El Colegio de México, 1997, 189-212.

Informe de la Comisión Pesquisidora de la frontera norte al ejecutivo de la Unión sobre depredaciones de los indios y otros males que sufre la frontera mexicana, México, Imprenta de León y White, 1874.

Plan de Defensa de los Estados invadidos por los bárbaros, propuesto por la Junta de Representantes, creada por la Ley de 24 de abril del presente año, México, 1849.

Plan para la defensa del Estado de Coahuila invadido por los bárbaros. Propuesto por los representantes de Monclova, Río Grande y Parras que lo suscriben, y adoptado por la comisión respectiva quien la presentó al $\mathrm{H}$. Congreso en 25 de agosto de 1849, Saltillo, 1849.

Rivaya-Martínez, Joaquín: Captivity and adoption among the comanche indians, 1700-1875, Los Angeles, University of California, 2006.

Rodríguez, Martha: La guerra entre bárbaros y civilizados. El exterminio del nómada en Coahuila 1840-1880, Saltillo, CESHAC, 1998.

Sheridan Prieto, Cecilia: «Coahuila y la invasión norteamericana», en Vázquez (coord.), México al tiempo de su guerra con Estados Unidos, 1997, 157-188.

Schumacher, Ma. Esther (comp.): Mitos en las relaciones México-Estados Unidos, México, Secretaría de Relaciones Exteriores/ FCE, 1994.

Vázquez, Josefina Zoraida: La supuesta República de Río Grande, Ciudad Victoria, Instituto de Investigaciones Históricas/ Universidad Autónoma de Tamaulipas, 1995.

Vázquez, «México y la guerra con Estados Unidos», en Vázquez (coord.), México al tiempo de su guerra con Estados Unidos, 1997, 17-48.

Vázquez, La guerra entre México y Estados Unidos: 1846-1848. Cuatro miradas, México, El Colegio de San Luis, 1998.

Vázquez, Josefina Zoraida y Meyer, Lorenzo: México frente a Estados Unidos: un ensayo histórico 1776-2000, México, FCE, 2006.

Velasco Ávila, Cuauhtémoc: En manos de los bárbaros. Testimonios de la guerra india en el noreste, México, Breve Fondo Editorial, 1996.

Velasco Ávila, La amenaza comanche en la frontera mexicana, 1800-1841, México, Universidad Nacional Autónoma de México, 1998.

Velasco Ávila, «"Nuestros obstinados enemigos”»: ideas e imágenes de los indios nómadas en la frontera noreste mexicana, 1821-1840», en Nómadas y sedentarios en el norte de México. Homenaje a Beatriz Braniff, México, Universidad Nacional Autónoma de México, 2000, 441-459. 
Velasco Avila, «La historia de los nómadas y sus fuentes», en Los andamios del historiador. Construcción y tratamiento de fuentes, Camarena, Mario y Villafuerte, Lourdes (coords.), México, AGN/ INAH, 2001, 161-173.

Weber, David J.: La frontera norte de México, 1821-1846. El sudoeste americano en su época mexicana, México, FCE, 1988. 